Wagtendonk, I. van, Smits, M., Merten, H., Heetveld, M.J., Wagner, C. Nature, causes and consequences of unintended events in surgical units. British Journal of Surgery: 2010, 97(11), $1730-1740$

\begin{tabular}{|l|l|}
\hline $\begin{array}{l}\text { Postprint } \\
\text { Version }\end{array}$ & 1.0 \\
\hline Journal website & http://onlinelibrary.wiley.com/doi/10.1002/bjs.7201/full \\
\hline Pubmed link & http://www.ncbi.nlm.nih.gov/pubmed/20661930 \\
\hline DOI & $10.1002 /$ bjs.7201 \\
\hline
\end{tabular}

This is a NIVEL certified Post Print, more info at http://www.nivel.eu

\title{
Nature, causes and consequences of unintended events in surgical units
}

\author{
I. VAN WAGTENDONK ${ }^{1, *}$, M. SMits ${ }^{1}$, H. MERTEN ${ }^{1}$, M. J. HeETVELD ${ }^{2}$, C. WAGNER ${ }^{1,3}$ \\ ${ }^{1}$ Netherlands Institute for Health Services Research (NIVEL), Utrecht, The Netherlands \\ ${ }^{2}$ Department of Surgery, Kennemer Gasthuis, Haarlem, The Netherlands \\ ${ }^{3}$ Department of Public and Occupational Health, EMGO Institute for Health and Care \\ Research, VU University Medical Centre, Amsterdam, The Netherlands
}

\begin{abstract}
Background: Several studies have shown that the rate of unintended harm is higher in surgical than in non-surgical care. To improve patient safety in surgery, information about the underlying causes is needed. This observational study examined the nature, causes and consequences of unintended events in surgical units, and the completeness of event reporting.

Methods: Ten surgical units in the Netherlands participated. The study period per unit was 8-14 weeks, during which healthcare providers reported unintended events. Event reports were analysed with a root cause analysis tool (PRISMA). In addition, an independent surgeon reviewed about 40 patient records of patients in each surgical unit to examine whether an unintended event had occurred.

Results: A total of 881 unintended events were reported and analysed, of which 33.0 per cent were categorized as medication events. Most root causes were human ( $72 \cdot 3$ per cent), followed by organizational ( $16 \cdot 1$ per cent) and technical ( 5.7 per cent). More than half of the events had consequences for the patient. Sixty-four unintended events were identified in a review of 320 patient records. Only one of these events was also reported by a healthcare provider.

Conclusion:

Event reporting and patient record review provide insight into diverse types of unintended events and complement each other. The information on unintended events from both sources may help target research and interventions to increase patient safety. Copyright (C) 2010 British Journal of Surgery Society Ltd. Published by John Wiley \& Sons, Ltd.
\end{abstract}

\section{INTRODUCTION}

Hospital care is developing continuously, increasing the opportunities for successful treatment. In recent decades, the number and complexity of diagnostic procedures and 
Wagtendonk, I. van, Smits, M., Merten, H., Heetveld, M.J., Wagner, C. Nature, causes and consequences of unintended events in surgical units. British Journal of Surgery: 2010, 97(11), 1730-1740

therapeutic interventions have increased markedly. More diseases can be treated successfully and vulnerable patients are more often receiving surgical treatment. The increasingly complicated techniques and innovations, however, also increase the potential for error. Errors can result in patient harm, leading to temporary or permanent disability or death (adverse events $)^{1}$. In a recent systematic review by De Vries and colleagues ${ }^{2}$, the median overall incidence of in-hospital adverse events was calculated, based on eight patient record review studies. One or more adverse events occurred in $9 \cdot 2$ per cent of all hospital admissions. Nearly half ( 43.5 per cent) of the adverse events were preventable and $7 \cdot 4$ per cent contributed to death.

Surgical care can involve complex and high-risk treatments. Several record review studies have shown that a high percentage of adverse events are attributable to surgical specialties, ranging from 51 to 79 per cent of all adverse events ${ }^{3-8}$. More than half of these events appear preventable. The high rates of adverse events for surgical procedures support the need for interventional strategies and monitoring ${ }^{9}$. An increase in patient safety can be achieved only if interventions tackle the right causes. More insight into the causes underlying surgical events is still needed.

A range of methodologies is available for studying patient safety and the causes of unintended events in hospitals. Unintended events are a broader group of events than adverse events; they are not restricted to errors that result in patient harm, but also include near misses. Near misses are believed to share the same underlying failure factors as accidents that do affect the patient (adverse events) ${ }^{10},{ }^{11}$. Near misses occur relatively frequently, providing more opportunities to gather information about the nature and causes of unintended events.

Michel and colleagues ${ }^{12}$ compared retrospective record review (data collected from patient records after discharge) with prospective methods (data collected during hospital stay, for example through staff reporting of unintended events) and concluded that record review is more appropriate for estimating rates of adverse events, whereas prospective methods should be preferred for describing causes of events. Sari and co-workers ${ }^{13}$ compared event reporting with the record review method and concluded that routine reporting systems considerably underreport the scale and severity of unintended events. The strength of event reporting is, however, in detecting latent failures (organizational and technical causes) that might not otherwise be apparent ${ }^{14},{ }^{15}$.

The main aim of the present study was to gain more insight into the nature, causes and consequences of unintended events in surgical units. An estimation of incidence rates was not the focus, as other studies have already reported on these. Because of the assumed ability to identify active as well as latent failures, event reports were chosen as input for the study. However, because of the believed underreporting of serious events in voluntary event reporting ${ }^{13},{ }^{16}$, unintended events were also studied by means of patient record review. The secondary study aim was to test the completeness of voluntary event reporting by comparing the results of event reporting with those of patient record review.

\section{METHODS}

An observational study was carried out between December 2006 and December 2007 to examine unintended events in ten surgical units of hospitals in the Netherlands: one university hospital, five tertiary teaching hospitals and four general hospitals. The study protocol was granted ethical approval by the VU University Medical Centre review board in Amsterdam.

The study period per unit was 8-14 weeks, depending on the reporting speed. Healthcare providers (nurses, resident physicians, medical consultants) in the unit were asked to report all unintended events directly after the event had occurred or was discovered. Unintended events were broadly defined as all events, no matter how seemingly trivial or commonplace, that were unintended and could have harmed or did harm a patient ${ }^{17}$. Important criteria were 
Wagtendonk, I. van, Smits, M., Merten, H., Heetveld, M.J., Wagner, C. Nature, causes and consequences of unintended events in surgical units. British Journal of Surgery: 2010, 97(11), 1730-1740

that the healthcare providers were involved in the event (during its occurrence or afterwards) and that the event was related to safety in patient care.

To find the causes underlying the reported unintended events, the events were analysed by a trained and experienced researcher using a root cause analysis tool called PRISMAMedical $^{18},{ }^{19}$. In addition, the unintended events were classified into one of eight categories that were formulated after completion of the study by looking at common themes in the reported events: materials and equipment, diagnosis and treatment, medication, protocols and regulations, incorrect data and substitutions, collaboration with resident physicians and medical consultants, collaboration with other departments, and other.

Completeness of event reporting was assessed by review of about 40 patient records per surgical unit in the same research period to see whether an unintended event had been documented.

The unit of analysis in the reports provided by healthcare providers as well as in the patient records was an 'event'. The focus was on comparing the nature of unintended events and not the incidence. Therefore, a comparable denominator was not needed. The number of matches between reports and patient records was assessed.

\section{Data collection}

\section{Reporting procedure}

Before the start of the study, staff received oral and written instruction about the aim and procedures of the study. They had two alternatives for reporting unintended events: a pocketsized report card or a report form. On the report card, the name of the reporter, the moment in time and a description of the event were requested. The report form was more elaborate and additionally requested the involvement of the reporter, the phase of care, place, some patient characteristics and consequences for the patient. The reporters used the report card when they had no time to write down all details about the event. A locked mailbox was placed in the team or resident room for collection of report cards and forms.

A minimum of 50 reports per surgical unit was sought because, when the number of reports is at least 50 , the variety of possible unintended events will be captured and a valid causal factor profile can be drawn (T. W. van der Schaaf, personal communication). Healthcare professionals were encouraged to report unintended events by a 2-weekly newsletter, reminders during team meetings and by means of other activities designed to bring reporting to their attention.

Once or twice a week a researcher or trained nurse from outside the hospital visited the surgical unit to collect the written reports, and ask the reporters questions about the reported events and their contributing factors during short interviews. When the event had been registered on a report card, this interview took more time than when the detailed report form had been completed beforehand. No interviews were held with staff in hospital units other than the participating surgical unit.

\section{PRISMA analysis}

All unintended events were analysed by a trained researcher using Preferred Reporting Items for Systematic Reviews and Meta-Analyses (PRISMA)-Medical. PRISMA is a tool used to analyse the root causes of a broad set of unintended events ${ }^{18},{ }^{19}$. The corresponding taxonomy to classify the root causes, the Eindhoven Classification Model (ECM), was used as a foundational component in the conceptual framework for the World Health Organization World Alliance for Patient Safety's International Classification for Patient Safety ${ }^{20},{ }^{21}$. It is based on the system approach to human error of Reason ${ }^{22},{ }^{23}$ and the skill-rules-knowledgebased behaviour model of Rasmussen ${ }^{24}$.

PRISMA examines the relative contributions of latent factors (technical and organizational), active failures (human) and other factors (patient related and other). Unintended events are analysed in three main steps. First, a causal tree is formulated; Fig. 1 
Wagtendonk, I. van, Smits, M., Merten, H., Heetveld, M.J., Wagner, C. Nature, causes and consequences of unintended events in surgical units. British Journal of Surgery: 2010, 97(11), 1730-1740

shows an example. A short description of the event is placed at the top of the tree, as the starting point for the analysis. Below the top event, all involved direct causes are mentioned. These direct causes often have their own causes. By continuing to ask 'why' for each event or action, beginning with the top event, all relevant causes are revealed. In this way a structure of causes arises, until the root causes are identified at the bottom of the tree. In the present study, this first phase was ended when no more factual information about underlying causes was available. Reporters' presumptions about the possible causes were not recorded in the causal tree. Lack of organizational or technical barriers was not labelled as an organizational or technical cause. For example, an electronic signalling system for registration of medication can prevent an allergic reaction or the administration of more medication than prescribed, but as long as such a system does not exist, this system can and will not be regarded as a cause. However, improvements in organizational procedures or techniques can arise from the identification of human errors. In the second phase, the identified root causes are classified with the ECM. This distinguishes five main categories and 20 subcategories (Table1). Finally, by aggregating the classifications of root causes of at least 50 events, a so-called PRISMA profile (quantitative database) can be delineated, which is a graphical representation of the relative contributions of the different root causes and gives direction to the development of preventive strategies ${ }^{18},{ }^{19}$. A causal factor that occurs relatively frequently raises a sense of urgency to intervene in this specific area.

\section{[FIGURE 1]}

\section{[TABLE1]}

A previous publication reported on the inter-rater reliability (between PRISMA analysts) of formulating root causes in causal trees and classifying the root causes with the $\mathrm{ECM}^{25}$. The reliability analyses were performed with a sample of event reports from a larger database of events than used for the present study. In addition to the current surgery reports, this database also contained reports from emergency and internal medicine units. The agreement in formulating root causes of unintended events, expressed as a mean score ranging from 0 to 3 , was good $(2 \cdot 0$ overall, $2 \cdot 1$ for surgery). The inter-rater reliability for the number of root causes used in the causal tree was moderate ( $\kappa=0.45$ overall, $\kappa=0.49$ for surgery). The inter-rater reliability of classifying root causes with the ECM taxonomy was moderate to substantial at main category $(\kappa=0.70$ overall, $\kappa=0.45$ for surgery) and subcategory (complete taxonomy) ( $\kappa=0.63$ overall, $\kappa=0.56$ for surgery) levels.

\section{Patient record review}

To check the completeness of the event reporting, four trained and experienced surgeons from outside the hospital reviewed the records of about 40 patients in each surgical unit who had been admitted in the research period to see whether an unintended event had occurred. In advance, a researcher or one of the nurses working in the unit asked (surgical) patients to give informed consent for their data to be used. If consent was obtained, the patient record was screened by the surgeon using a standard review form to assess whether the patient's care deviated from current medical guidelines and, more specifically, to determine whether an adverse event or near miss had occurred and whether the adverse event was preventable. The review form was based on the well known protocol developed by the Harvard Medical Practice Study ${ }^{26}$, which has been shown to produce reliable and valid judgements of adverse events $^{27}$. Sampled patient records were reviewed by one of the four surgeons; there was no screening in advance using triggers.

The sample size was based on an estimated population size of 330 patients per unit over 8 weeks at the planning stage. The expected prevalence of events of interest was at least 6-7 per cent ${ }^{8}$. Furthermore, an error rate of \pm 2 per cent was feasible and acceptable in the context 
Wagtendonk, I. van, Smits, M., Merten, H., Heetveld, M.J., Wagner, C. Nature, causes and consequences of unintended events in surgical units. British Journal of Surgery: 2010, 97(11), 1730-1740

of the research. Therefore, the required sample size was between 32 and 46 cases $^{28}$. A sample size of 40 patient records was chosen.

An adverse event was defined as an unintended injury that resulted in temporary or permanent disability, death or prolonged hospital stay, and was caused by healthcare management rather than the patient's disease ${ }^{3}, 4,7,8,26$. Preventable adverse events are the result of healthcare below professional standards and by healthcare system failures ${ }^{3}{ }^{6-8}$. The degree of preventability of the adverse events was measured on a six-point scale: (virtually) no evidence for preventability; slight to modest evidence of preventability; preventability not very likely (less than 50-50 but 'close call'); preventability more than likely (more than 5050 but 'close call'); strong evidence of preventability; or (virtually) certain evidence of preventability ${ }^{29}$. The judgements were based on clinical experience, professional norms and the expert opinion of the expert reviewers. There had to be some evidence of preventability in the patient record, such as signs of deterioration of the patient, but no action by the healthcare professional. A near miss was defined as an act of commission or omission that could have harmed the patient but was prevented from completion by a planned or unplanned recovery ${ }^{30-32}$.

\section{Statistical analysis}

Data from the event reports and record review were summarized by frequency tables and descriptive statistics using SPSS ${ }^{\circledR}$ version 14.0 (SPSS, Chicago, Illinois, USA).

\section{RESULTS}

\section{Event reporting}

\section{Characteristics of reports}

A total of 881 unintended events were reported in the ten participating surgical units, with a mean(s.d.) of 88(44) (range 36-180) reports per unit. One unit had only 36 reports, and did not reach the 50 reports aimed for. Because separate causal factors were not analysed at unit level in this study, reports from this unit were included in analysis of the aggregated data. Most reports were made by nurses ( 92.0 per cent); resident physicians or medical specialists reported 8.0 per cent of the unintended events. In 55.4 per cent of the unintended events the reporter was directly involved in or witnessed the event. In the remaining 44.6 per cent, the event was discovered afterwards. For example, a nurse noticed that the intravenous drip had been adjusted wrongly by another nurse during the previous shift. More than one in three incidents occurred in the phase of care of medication supply (Table2).

\section{[TABLE 2]}

\section{Types of unintended event}

All 881 unintended events were classified into one of eight event categories. Table 3 shows the types of event reported, with examples. A third of the events were related to medication ( 33.0 per cent); unintended events occurring during preparation, administration and registration of medication were all categorized as medication events. Some $15 \cdot 6$ per cent of the unintended events involved problems with materials or equipment, such as defective equipment or absence of materials.

\section{[TABLE 3]}

Consequences for patients 
Wagtendonk, I. van, Smits, M., Merten, H., Heetveld, M.J., Wagner, C. Nature, causes and consequences of unintended events in surgical units. British Journal of Surgery: 2010, 97(11), 1730-1740

In 547 (62.1 per cent) of 881 events there were consequences for the patient (Table4). Only 5.6 per cent of events involved physical injuries, for example gastric bleeding when a protective drug had not been administered or renal insufficiency because a patient did not have adequate fluid intake or intravenous supplementation. Consequences mainly concerned suboptimal care $(41.3$ per cent) or inconvenience $(25 \cdot 1$ per cent). An example of suboptimal care is a delay in starting the prescribed medication or administering less medication than prescribed (without observed consequences). Examples of inconvenience are unnecessarily being stopped from eating and drinking before operation, and long waiting times (for medical consultant, physical examination, X-ray).

\section{[TABLE 4]}

\section{Root causes of unintended events}

All 881 unintended events were analysed with PRISMA, resulting in 1250 root causes. Almost two-thirds of the events (63.7 per cent) had a single root cause, 31.3 per cent had two, 4.4 per cent had three and 0.6 per cent had four root causes. The mean(s.d.) number of root causes per unintended event was $1 \cdot 4(0 \cdot 6)$.

Of all root causes, 72.3 per cent were human, $16 \cdot 1$ per cent organizational, $5 \cdot 7$ per cent technical and 5.9 per cent were related to the patient or other factors. Fig. 2 shows the percentages of causes at the subcategory level.

Figure 2. Box and whisker plots showing root causes in ten surgical units (root cause profile). The five main categories of root cause (technical, organizational, human, patient related and other/unclassifiable) are divided into 20 subcategories. Full descriptions of the categories are given in Table1. Mean values, median values, interquartile ranges and ranges (excluding outliers) are represented by circles, bold horizontal bars, boxes and error bars respectively. Outliers (more than 1.5 times the interquartile range) are represented by asterisks. A large box means that there is wide variation between units in the frequency of these root causes

\section{[FIGURE 2]}

Both the largest mean frequency and the largest variation between surgical units was found within the category human-rule-based behaviour-intervention (HRI). These are failures that result from faulty task planning and execution. This particularly concerned failures in the administration of drugs (providing medication to the wrong patient or prescribing a wrong dose), forgetting to make or cancel an appointment, not replenishing materials after use or not cleaning up materials.

The category human-external (H-ex) also occurred relatively frequently. These events are human failures originating beyond the control and responsibility of the investigating unit (individuals in another department or another organization). One unit was an outlier in this category. In this unit, almost half of all causes were classified as H-ex owing to frequent failures in the preparation of medication by the (hospital) pharmacy.

Another outlier was found in the category human-rule-based behaviour-coordination (HRC). This category represents failures in task coordination within a healthcare team. The surgical unit that produced this outlier had no procedures for checking the most recent medication list; everyone thought that someone else was responsible for this task.

The category human-rule-based behaviour-verification (HRV) comprises incorrect and incomplete assessment of a situation, including related conditions of the patient and materials to be used before starting the intervention. Two units were outliers. In these units, which had lower rates of HRV failure, there was a strict procedure regarding doublechecking before administering medication to a patient.

The most frequently occurring organizational category was organizational-culture (OC). This comprises failures resulting from a collective approach and its attendant modes of 
Wagtendonk, I. van, Smits, M., Merten, H., Heetveld, M.J., Wagner, C. Nature, causes and consequences of unintended events in surgical units. British Journal of Surgery: 2010, 97(11), 1730-1740

behaviour to risk. An example is having no priority for completing the patient record after discharge, with the result that parts of the record are missing or complete records are lost.

The most common technical category was technical-design (TD), which includes failures due to poor design or equipment, software, labels or forms. The design of the medication distribution system or medication card led to errors in some units.

\section{Patient record review}

A total of 320 patient records were reviewed. An unintended event was identified in one of five records $(64,20 \cdot 0$ per cent). In six instances it concerned a near miss. For example, according to the anaesthesia guidelines (American Society of Anesthesiologists grade III cardiovascular sickness) a preoperative plain chest X-ray was needed. This preoperative radiography was not performed, but had no consequences. The remaining 58 cases involved adverse events (see Table5 for examples). There was (virtually) no evidence for preventability in 40 per cent of these adverse events. Adverse events with no preventability were often wound infection or wound dehiscence, sometimes after discharge from hospital, with a subsequent readmission to hospital or additional treatment.

\section{[TABLE 5]}

In 22 per cent of patients the reviewers did find some indications for a potentially preventable injury, but the preventability was judged as low (7 per cent slight to modest evidence of preventability; 15 per cent preventability not very likely, less than 50-50 but 'close call'). A common theme in the low-preventability categories was severe peritonitis, resulting in further intervention and sometimes a prolonged hospital stay.

In 38 per cent of patients, the potential preventability was judged as high (14 per cent preventability more than likely, more than $50-50$, but 'close call'; 12 per cent strong evidence of preventability; 12 per cent (virtually) certain evidence of preventability). This often involved bleeding after surgery or missed diagnoses, which resulted in a prolonged hospital stay or further intervention, such as an operation.

The nature of the unintended events identified by voluntary reporting differed from that of the events identified by patient record review. The unintended events in the patient records were related mainly to medical care by resident physicians or medical consultants, whereas the unintended events reported voluntarily were related mainly to nursing care. Only one of the unintended events identified in the patient records was also reported by a healthcare provider in the unit during the voluntary reporting period.

\section{DISCUSSION}

This study has shown that a large number of unintended events reported in surgical units are related to medication, including preparation, administration and registration. This might be explained by a number of factors. First, the complexity of surgery frequently involves more complex medication. Second, there are often changes in medication policy during admission. Third, changes in shifts are known to increase the likelihood of errors. Residents and medical consultants can change medication independently at any time in the computer record, increasing the risk of false adjustments. Furthermore, medication-related events are not always caused by the surgical unit itself, but can also originate in collaborating departments, for example the hospital pharmacy. Double-checking is important to detect possible medication errors before they reach the patient. These checks may be omitted, for example because of time pressure.

Although most reported unintended events had no physical consequences for the patient, they often resulted in inconvenience to the patient or suboptimal care. This indicates that there is room for improving the quality of care, alongside improving the safety of care.

In all surgical units, the causes of the unintended events were mainly human, although there was often a combination of human and latent causal factors (organizational and technical). 
Wagtendonk, I. van, Smits, M., Merten, H., Heetveld, M.J., Wagner, C. Nature, causes and consequences of unintended events in surgical units. British Journal of Surgery: 2010, 97(11), 1730-1740

Many causes were external, originating outside the participating unit, indicating that healthcare for surgical patients depends on good collaboration between units and with other organizations.

Only one unintended event was identified by both event reporting and patient record review, meaning that the methods are complementary. The types of unintended event identified by event reporting differed from the types found in patient records. Event reporting was performed mainly by nurses and, consequently, the unintended event reports related mainly to nursing care and to a lesser extent to care processes by resident physicians and specialists. These latter groups of professionals do not generally perceive (surgical) complications to be 'reportable incidents'. They address complications in mortality and morbidity meetings ${ }^{22}$. The record review method provided more insight into medical care by resident physicians and specialists.

As a result of voluntary reporting, the unintended events identified in this study are not likely to be a random sample of all unintended events occurring in the surgical units. It is conceivable that certain mistakes were underreported because healthcare providers were embarrassed or afraid of condemnation by their colleagues or the researchers. Moreover, some unintended events occurred multiple times in one surgical unit, and there may have been reluctance to report these events repeatedly. It is unknown which events were underreported, how frequently they occurred and whether they had the same underlying causes in every instance. Therefore, it was not possible to correct for this underreporting by giving different weights to these types of events and their causes. However, after completing the study, the reported events were discussed with the participating units. They confirmed that the events reported were a good representation of the events that occur in their units. A substantial proportion of the unintended events was discovered afterwards. In these instances it was not always possible for the healthcare provider to give detailed information about the event and its underlying causes. This often led to the identification of only human causes, these being the most visible factors. Moreover, even when the reporter was directly involved, information gained in later interviews depended on the recall of the reporter. During the study, however, the researchers strived for a small time lag between the occurrence of the event and the interview, to decrease the likelihood of memory failure.

The causal trees in the present study were relatively small, with a mean of 1.4 root causes per event. There are two possible explanations for this. First, not only adverse events (with harm for patients) were examined but predominantly minor unintended events. Adverse events probably result in larger causal trees because of their inherent complexity; often many causal factors are involved simultaneously. The unintended events examined in the present study included small deviations from standard practice, with often only a few root causes. A second explanation for the relatively small causal trees is that only members of staff in the participating units were interviewed about reported events and not staff from other collaborating departments. This made the execution of the study more practical. Moreover, safety advice at unit level was the ultimate goal. When the PRISMA analysis revealed causes present in other units, they were classified as external. It is possible that an external factor had more underlying root causes, but these were not examined. Finally, for the record review study, it is possible that the four reviewing surgeons varied in their judgement of the presence of an unintended event and its preventability. However, because of the training the reviewers had received and their considerable experience in reviewing patient records gained in previous related studies, the reliability of the reviews is likely be sufficient. In addition, the surgeons discussed difficult cases with each other.

The present results show some similarities with previous studies of event reports. Olsen and colleagues $^{33}$ and Nuckols et al. ${ }^{34}$ also found that the majority of the event reports were made by nurses. Moreover, Olsen and co-workers examined the extent of overlap between event reporting and record review. They found 64 unintended events in 288 patient records and compared these with the results from voluntary event reporting by healthcare providers. As in the present study, only one unintended event was identified by both methods. 
Wagtendonk, I. van, Smits, M., Merten, H., Heetveld, M.J., Wagner, C. Nature, causes and consequences of unintended events in surgical units. British Journal of Surgery: 2010, 97(11), 1730-1740

About a third of unintended events were related to medication. A predominance of medication events has been found in other studies too. A systematic review of patient record review studies showed that the second leading category of adverse events comprised drugrelated events (ranging from 11 to 24 per cent) ${ }^{2}$. In the event reporting study of Nuckols et al. ${ }^{34} 29$ per cent of the event reports appeared to be medication related.

Previously, 146 surgical adverse events reported by surgeons have been studied ${ }^{35}$. Human causes (cognitive factors) and system causes (such as excessive workload, technology failures and inappropriate protocols) jointly contributed to 86 per cent of the events. In contrast, in the present study, event reporting was carried out mainly by nurses and comprised unintended events (often without patient harm) instead of adverse events, giving different root causes.

Although the causes of the reported unintended events were mainly human, latent factorsorganizational and technical - were established as well, in spite of the difficulty in identifying them. Believing that an interaction between latent and active conditions contributes to the occurrence of failure following Reason's system approach, investigation of effective system interventions to improve patient safety in surgery is recommended.

The main issue in patient safety in surgical units is medication. Suggestions on how medication safety is to be enhanced are described in the literature ${ }^{36}$. Medication errors may be reduced, for example, by use of computerized physician code entry ${ }^{37-39}$, bar-coding ${ }^{40},{ }^{41}$, clinical decision support systems ${ }^{42}$, ward pharmacy teams $s^{43}$ and structured order sheets ${ }^{44}$. The effectiveness of combinations of these interventions has not been tested systematically. Event reporting gives insight into both latent and active failures, and 'smaller' unintended events that did not affect the patient, but it mainly concerns events related to nursing care. Expanding event reporting with patient record review results in a more comprehensive view of unintended events related to physician/medical specialist care. Both methods are valuable and complement each other when examining the nature, causes and consequences of unintended events in hospitals ${ }^{32}$.

\section{ACKNOWLEDGEMENTS}

The authors thank everyone who contributed to the study, including the staff of the participating surgical units, and the researchers and nurses who helped with data collection. The Dutch Patient Safety Research Programme was initiated by the Dutch Society of Medical Specialists (Orde van Medisch Specialisten) with financial support from the Ministry of Health, Welfare and Sport. The programme is carried out by the EMGO+ Institute/VU University Medical Centre Amsterdam and Netherlands Institute for Health Services Research (NIVEL). The authors declare no conflict of interest.

\section{REFERENCES}

1 World Health Organization. World Alliance for Patient Safety Forward Programme 2005.

World Health Organization: Geneva, 2004.

2 de Vries EN, Ramrattan MA, Smorenburg SM, Gouma DJ, Boermeester MA. The incidence and nature of in-hospital adverse events: a systematic review. Qual Saf Health Care 2008; 17: 216-223.

3 Wilson RM, Runciman WB, Gibberd RW, Harrison BT, Newby L, Hamilton JD. The quality in Australian health care study. Med J Aust 1995; 163: 458-471.

4 Thomas EJ, Studdert DM, Burstin HR, Orav EJ, Zeena T, Williams EJ et al. Incidence and types of adverse events and negligent care in Utah and Colorado. Med Care 2000; 38: 261-271.

5 Vincent C, Neale G, Woloshynowych M. Adverse events in British hospitals: preliminary retrospective record review. BMJ 2001; 322: 517-519.

6 Davis P, Lay-Yee R, Briant R, Ali W, Scott A, Schug S. Adverse events in New Zealand public hospitals II: preventability and clinical context. N Z Med J 2003; 116: U624. 
Wagtendonk, I. van, Smits, M., Merten, H., Heetveld, M.J., Wagner, C. Nature, causes and consequences of unintended events in surgical units. British Journal of Surgery: 2010, 97(11), ? 1730-1740

7 Baker GR, Norton PG, Flintoft V, Blais R, Brown A, Cox J et al. The Canadian Adverse Events Study: the incidence of adverse events among hospital patients in Canada. CMAJ 2004; 170: 1678-1686.

8 Zegers M, De Bruijne MC, Wagner C, Hoonhout LH, Waaijman R, Smits M et al. Adverse events and potentially preventable deaths in Dutch hospitals: results of a retrospective patient record review study. Qual Saf Health Care 2009; 18: 297-302.

9 Kable AK, Gibberd RW, Spigelman AD. Adverse events in surgical patients in Australia. Int J Qual Health Care 2002; 14: 269-276.

10 Kanse L, van der Schaaf TW, Vrijland ND, van Mierlo H. Error recovery in a hospital pharmacy. Ergonomics 2006; 49: 503-516.

11 Wright $L$, van der Schaaf T. Accident versus near miss causation: a critical review of the literature, an empirical test in the UK railway domain, and their implications for other sectors. J Hazard Mater 2004; 111: 105-110.

12 Michel P, Quenon JL, de Sarasqueta AM, Scemama O. Comparison of three methods for estimating rates of adverse events and rates of preventable adverse events in acute care hospitals. BMJ 2004; 328: 199.

13 Sari AB, Sheldon TA, Cracknell A, Turnbull A. Sensitivity of routine system for reporting patient safety incidents in an NHS hospital: retrospective patient case note review. BMJ 2007; 334: 79.

14 Thomas EJ, Petersen LA. Measuring errors and adverse events in health care. J Gen Intern Med 2003; 18: 61-67.

Direct Link:

15 Helmreich RL. On error management: lessons from aviation. BMJ 2000; 320: 781-785.

16 Cullen DJ, Bates DW, Small SD, Cooper JB, Nemeskal AR, Leape LL. The incident reporting system does not detect adverse events: a problem for quality improvement. Jt Comm J Qual Improv 1995; 21: 541-548.

17 Bhasale AL, Miller GC, Reid SE, Britt HC. Analysing potential harm in Australian general practice: an incident-monitoring study. Med J Aust 1998; 169: 73-76.

18 van Vuuren W, Shea CE, van der Schaaf TW. The Development of an Incident Analysis Tool For the Medical Field. Eindhoven University of Technology: Eindhoven, 1997;

19 van der Schaaf TW, Habraken MMP: PRISM-Medical. A Brief Description. Eindhoven University of Technology, Faculty of Technology Management, Patient Safety Systems: Eindhoven, 2005;

20 World Alliance For Patient Safety Drafting Group, Sherman H, Castro G, Fletcher M; World Alliance for Patient Safety, Hatlie $M$ et al. Towards an International Classification for Patient Safety: the conceptual framework. Int J Qual Healthcare 2009; 21: 2-8.

21 Runciman W, Hibbert P, Thomson R, van der Schaaf T, Sherman H, Lewalle P. Towards an International Classification for Patient Safety: key concepts and terms. Int J Qual Health Care 2009; 21: 18-26.

22 Reason JT. Managing the Risk of Organisational Accidents. Ashgate: Aldershot, 1997. 23

Reason JT. Human Error. Cambridge University Press: Cambridge, 1990.

24 Rasmussen J. Skills, rules and knowledge: signals, signs and symbols and other distinctions in human performance models. IEEE Trans Systems Man Cybernetics 1983; 13: 257-266.

25 Smits M, Janssen J, de Vet R, Zwaan L, Timmermans D, Groenewegen P et al. Analysis of unintended events in hospitals: inter-rater reliability of constructing causal trees and classifying root causes. Int J Qual Saf Health Care 2009; 21: 292-300.

26 Brennan TA, Leape LL, Laird NM, Hebert L, Localio AR, Lawthers AG et al. Incidence of adverse events and negligence in hospitalized patients. Results of the Harvard Medical Practice Study I. N Engl J Med 1991; 324: 370-376.

27 Brennan TA, Localio RJ, Laird NL. Reliability and validity of judgments concerning adverse events suffered by hospitalized patients. Med Care 1989; 27: 1148-1158.

28 Robinson L, Neutons JJ. Research Techniques for the Health Sciences. MacMillan: New York, 1987; 366.

29 Zegers M, De Bruijne MC, Wagner C, Groenewegen PP, Waaijman R, Van der Wal G. Design of a retrospective patient record study on the occurrence of adverse events among patients in Dutch hospitals. BMC Health Serv Res 2007; 7: 27. 
Wagtendonk, I. van, Smits, M., Merten, H., Heetveld, M.J., Wagner, C. Nature, causes and consequences of unintended events in surgical units. British Journal of Surgery: 2010, 97(11), 1730-1740

30 Kaplan HS, Fastman BR. Organization of event reporting data for sense making and system improvement. Qual Saf Health Care 2003; 12: ii68-ii72.

31 Battles JB, Lilford RJ. Organizing patient safety research to identify risks and hazards. Qual Saf Health Care 2003; 12: ii2-ii7.

32 van der Schaaf TW. Near Miss Reporting in the Chemical Process Industry (Dissertation). Eindhoven University of Technology: Eindhoven, 1992.

33 Olsen S, Neale G, Schwab K, Psaila B, Patel T, Chapman EJ et al. Hospital staff should use more than one method to detect adverse events and potential adverse events: incident reporting, pharmacist surveillance and local real-time record review may all have a place. Qual Saf Health Care 2007; 16: 40-44.

34 Nuckols TK, Bell DS, Liu H, Paddock SM, Hilborne LH. Rates and types of events reported to established incident reporting systems in two US hospitals. Qual Saf Health Care 2007; 16: 164-168.

35 Gawande AA, Thomas EJ, Zinner MJ, Brennan TA. The incidence and nature of surgical adverse events in Colorado and Utah in 1992. Surgery 1999; 126: 66-75.

36 Dückers M, Faber M, Cruijsberg J, Grol R, Schoonhoven L, Wensing M. Safety and risk management interventions in hospitals: a systematic review of the literature. Med Res Rev 2009; 66: 90S-119S.

37 King WJ, Paice N, Rangrej J, Forestell GJ, Swartz R. The effect of computerized physician order entry on medication errors and adverse drug events in pediatric inpatients. Pediatrics 2003; 112: 506-509.

38 Voeffray M, Pannatier A, Stupp R, Fucina N, Leyvraz S, Wasserfallen JB. Effect of computerisation on the quality and safety of chemotherapy prescription. Qual Saf Health Care 2006; 15: 418-421.

39 Walsh KE, Landrigan CP, Adams WG, Vinci RJ, Chessare JB, Cooper MR et al. Effect of computer order entry on prevention of serious medication errors in hospitalized children. Pediatrics 2008; 121: e421-e427.

40 Paoletti RD, Suess TM, Lesko MG, Feroli AA, Kennel JA, Mahler JM et al. (2007). Using barcode technology and medication observation methodology for safer medication administration. Am J Health Syst Pharm 2007; 64: 536-543.

41 Poon EG, Cina JL, Churchill W, Patel N, Featherstone E, Rothschild JM et al. Medication dispensing errors and potential adverse drug events before and after implementing bar code technology in the pharmacy. Ann Intern Med 2006; 145: 426-434.

42 Berner ES, Houston TK, Ray MN, Allison JJ, Heudebert GR, Chatham WW et al. Improving ambulatory prescribing safety with a handheld decision support system: a randomized controlled trial. Am J Med Inform Assoc 2006; 13: 171-179.

43 Fertleman M, Barnett N, Patel T. Improving medication management for patients: the effect of a pharmacist on post-admission ward rounds. Qual Saf Health Care 2005; 14 : 207-211.

44 Kozer E, Scolnik D, MacPherson A, Rauchwerger D, Koren G. Using a preprinted order sheet to reduce prescription errors in a pediatric emergency department: a randomized, controlled trial. Pediatrics 2005; 116: 1299-1302. 
Wagtendonk, I. van, Smits, M., Merten, H., Heetveld, M.J., Wagner, C. Nature, causes and consequences of unintended events in surgical units. British Journal of Surgery: 2010, 97(11) 1730-1740

\section{TABLES AND FIGURES}

Figure 1

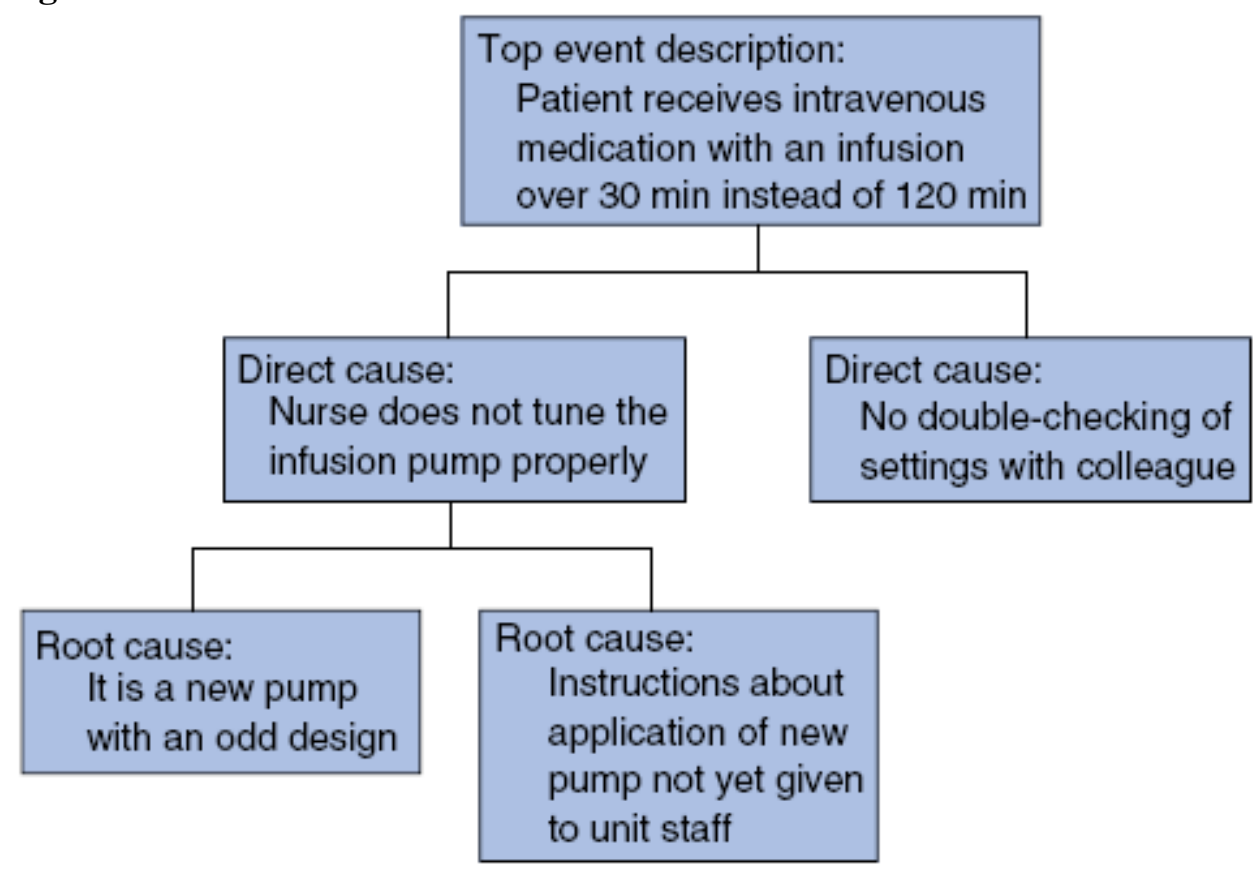

Fig. 1 Example of a causal tree 
Wagtendonk, I. van, Smits, M., Merten, H., Heetveld, M.J., Wagner, C. Nature, causes and consequences of unintended events in surgical units. British Journal of Surgery: 2010, 97(11), $1730-1740$

\section{Table 1}

Table 1 Description of categories of the Eindhoven Classification Model: PRISMA-Medical version ${ }^{18,19}$

\begin{tabular}{|c|c|c|c|}
\hline Main category & Subcategory & Code & Description \\
\hline \multicolumn{4}{|l|}{ Latent conditions } \\
\hline \multirow[t]{4}{*}{ Technical } & External & T-ex & $\begin{array}{l}\text { Technical failures beyond the control and responsibility of the investigating } \\
\text { organization }\end{array}$ \\
\hline & Design & TD & Failures due to poor design of equipment, software, labels or forms \\
\hline & Construction & TC & Correct design, but not constructed properly or set up in inaccessible areas \\
\hline & Materials & TM & Material defects not classified under TD or TC \\
\hline \multirow[t]{5}{*}{ Organizational } & External & O-ex & $\begin{array}{l}\text { Failures at an organizational level beyond the control and responsibility of the } \\
\text { investigating organization, such as in another department or area (address } \\
\text { by collaborative systems) }\end{array}$ \\
\hline & $\begin{array}{l}\text { Transfer of } \\
\text { knowledge }\end{array}$ & OK & $\begin{array}{l}\text { Failures resulting from inadequate measures taken to ensure that situational } \\
\text { or domain-specific knowledge or information is transferred to all new or } \\
\text { inexperienced staff }\end{array}$ \\
\hline & Protocols & $\mathrm{OP}$ & $\begin{array}{l}\text { Failures relating to the quality and availability of protocols within the } \\
\text { department (too complicated, inaccurate, unrealistic, absent or poorly } \\
\text { presented) }\end{array}$ \\
\hline & $\begin{array}{l}\text { Management } \\
\text { priorities }\end{array}$ & OM & $\begin{array}{l}\text { Internal management decisions in which safety is relegated to an inferior } \\
\text { position when faced with conflicting demands or objectives. This is a } \\
\text { conflict between production needs and safety. Example: decisions made } \\
\text { about staffing levels }\end{array}$ \\
\hline & Culture & $\mathrm{OC}$ & $\begin{array}{l}\text { Failures resulting from collective approach and its attendant modes of } \\
\text { behaviour to risk in the investigating organization }\end{array}$ \\
\hline \multicolumn{4}{|l|}{ Active errors } \\
\hline Human & External & $\mathrm{H}-\mathrm{ex}$ & $\begin{array}{l}\text { Human failures originating beyond the control and responsibility of the } \\
\text { investigating organization. This could apply to individuals in another } \\
\text { department }\end{array}$ \\
\hline $\begin{array}{l}\text { Knowledge-based } \\
\text { behaviour }\end{array}$ & $\begin{array}{l}\text { Knowledge-based } \\
\text { behaviour }\end{array}$ & HKK & $\begin{array}{l}\text { The inability of an individual to apply his or her existing } \\
\text { knowledge to a novel situation. Example: a trained } \\
\text { blood bank technologist who is unable to solve a } \\
\text { complex antibody identification problem }\end{array}$ \\
\hline \multirow[t]{5}{*}{$\begin{array}{l}\text { Rule-based } \\
\text { behaviour }\end{array}$} & Qualifications & HRQ & $\begin{array}{l}\text { The incorrect fit between an individual's training or } \\
\text { education and a particular task. Example: expecting a } \\
\text { technician to solve the same type of difficult problem } \\
\text { as a technologist }\end{array}$ \\
\hline & Coordination & HRC & $\begin{array}{l}\text { Lack of task coordination within a healthcare team in an organization. } \\
\text { Example: an essential task not being performed because everyone thought } \\
\text { that someone else had completed the task }\end{array}$ \\
\hline & Verification & HRV & $\begin{array}{l}\text { Correct and complete assessment of a situation including related conditions } \\
\text { of the patient and materials to be used before starting the intervention. } \\
\text { Example: failure to correctly identify a patient by checking the wristband }\end{array}$ \\
\hline & Intervention & HRI & $\begin{array}{l}\text { Failures that result from faulty task planning and execution. Example: } \\
\text { washing red cells by the same protocol as platelets }\end{array}$ \\
\hline & Monitoring & HRM & $\begin{array}{l}\text { Monitoring a process or patient status. Example: a trained technologist } \\
\text { operating an automated instrument and not realizing that a pipette } \\
\text { dispensing reagents is clogged }\end{array}$ \\
\hline \multirow[t]{2}{*}{$\begin{array}{l}\text { Skill-based } \\
\text { behaviour }\end{array}$} & Slips & HSS & $\begin{array}{l}\text { Failures in performance of highly developed skills. } \\
\text { Example: a technologist adding drops of reagents to a } \\
\text { row of test tubes and missing the tube, or a computer } \\
\text { entry error }\end{array}$ \\
\hline & Tripping & HST & $\begin{array}{l}\text { Failures in whole-body movements. These errors are often referred to as } \\
\text { 'slipping, tripping or falling'. Examples: a blood bag slipping out of one's } \\
\text { hands and breaking or tripping over a loose tile on the floor }\end{array}$ \\
\hline \multicolumn{4}{|l|}{ Other factors } \\
\hline Patient related & $\begin{array}{l}\text { Patient-related } \\
\text { factor }\end{array}$ & PRF & $\begin{array}{l}\text { Failures related to patient characteristics or conditions, which are beyond the } \\
\text { control of staff and influence treatment }\end{array}$ \\
\hline Other & Unclassifiable & $\mathrm{x}$ & Failures that cannot be classified in any other category \\
\hline
\end{tabular}


Wagtendonk, I. van, Smits, M., Merten, H., Heetveld, M.J., Wagner, C. Nature, causes and consequences of unintended events in surgical units. British Journal of Surgery: 2010, 97(11), 1730-1740

Table 2

Table 2 Characteristics of 881 reported unintended events

$\begin{array}{lr} & \begin{array}{r}\% \text { of unintended } \\ \text { events }\end{array} \\ \text { Event reported by } & 92.0 \\ \text { Nurse } & 8.0 \\ \text { Resident physician or medical specialist } & \\ \text { Involvement } & 55.4 \\ \text { Direct or witness } & 44.6 \\ \text { Afterwards } & 34.2 \\ \text { Phase of care } & 13.8 \\ \text { Medication supply } & 10.0 \\ \text { Transfer or discharge of patient } & 8.0 \\ \text { Examination or treatment } & 1.6 \\ \text { Preparation for the surgical operation } & 32.4 \\ \text { Acute situation } & \\ \text { Other } & \end{array}$

Table 3

Table 3 Types of 881 unintended events

\begin{tabular}{|c|c|c|}
\hline & $\begin{array}{l}\% \text { of unintended } \\
\text { events }\end{array}$ & Examples \\
\hline Medication & 33.0 & $\begin{array}{l}\text { Patient receiving wrong dose of heparin for } 15 \mathrm{~h} \\
\text { Gastric bleeding owing to omission of a prescription for medication } \\
\text { Intravenous drip mixed with morphine instead of heparin by the nurse }\end{array}$ \\
\hline Materials and equipment & $15 \cdot 6$ & $\begin{array}{l}\text { Materials out of stock } \\
\text { Materials not in the right place } \\
\text { Examinations cancelled because of defective radiology equipment }\end{array}$ \\
\hline Diagnosis and treatment & 11.1 & $\begin{array}{l}\text { No assessment of amylase in drain fluid } \\
\text { Resuscitation policy II (no resuscitation) noted in patient record without consulting patient } \\
\text { No treatment for patient with wounds (pressure ulcers) }\end{array}$ \\
\hline Collaboration with other departments & $10 \cdot 2$ & $\begin{array}{l}\text { Laboratory did not check patient's INR } \\
\text { Long waiting time for transport of patient to another department } \\
\text { Incomplete handover from recovery or other department to surgical unit }\end{array}$ \\
\hline $\begin{array}{l}\text { Collaboration with resident physicians } \\
\text { and medical consultants }\end{array}$ & 10.1 & $\begin{array}{l}\text { Difficult to contact resident or consultant } \\
\text { Neither physician nor anaesthetist took responsibility for administering pain relief to } \\
\text { terminally ill patient } \\
\text { Physician did not inform surgical unit about cancelled abdominal ultrasonography } \\
\text { appointment }\end{array}$ \\
\hline Incorrect data and substitutions & 5.9 & $\begin{array}{l}\text { Patient transported to operating room with wrong patient record } \\
\text { Check-up almost cancelled because of lack of verification of patient number or date of birth } \\
\text { Recovery nurse presented wrong patient to surgical department }\end{array}$ \\
\hline Protocols and regulations & 4.7 & $\begin{array}{l}\text { Staff not familiar with procedure in new protocol } \\
\text { No definite protocol for use of home medication } \\
\text { Inadequate observation of hygiene protocol }\end{array}$ \\
\hline Other & 9.4 & $\begin{array}{l}\text { Fall } \\
\text { Staff shortage } \\
\text { Loss of patient record }\end{array}$ \\
\hline Total & 100 & \\
\hline
\end{tabular}


Wagtendonk, I. van, Smits, M., Merten, H., Heetveld, M.J., Wagner, C. Nature, causes and consequences of unintended events in surgical units. British Journal of Surgery: 2010, 97(11), $1730-1740$

Table 4

Table 4 Consequences of 547 unintended events

\begin{tabular}{|lc|}
\hline Suboptimal care & $\begin{array}{c}\text { \% of unintended } \\
\text { events }^{*}\end{array}$ \\
\hline Inconvenience & 41.3 \\
Extra intervention & 25.1 \\
Prolonged hospital stay $(>24$ h) & 10.8 \\
Pain & 7.4 \\
Physical injury & 5.9 \\
Mental injury & 5.6 \\
Unknown & 5.6 \\
\hline
\end{tabular}

*Sum of percentages exceeds 100 per cent because of the possibility of two or more consequences per patient.

\section{Figure 2}

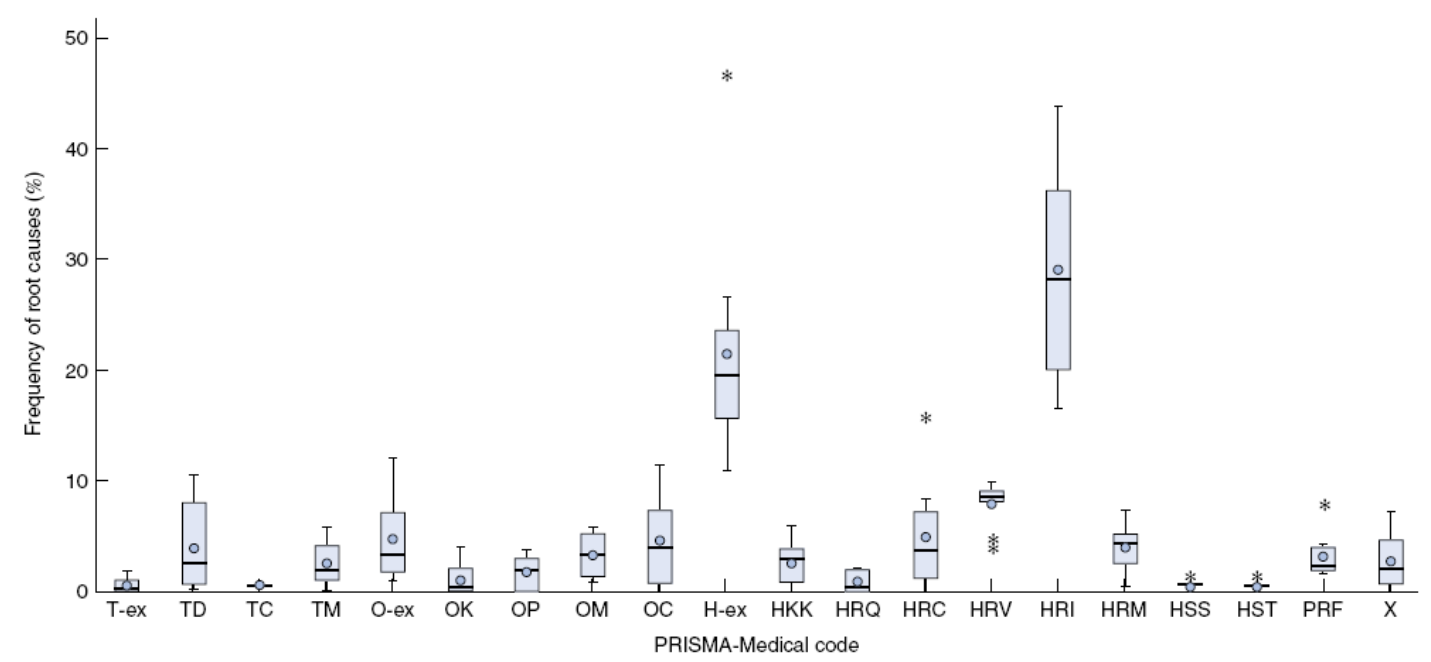

Fig. 2 Box and whisker plots showing root causes in ten surgical units (root cause profile). The five main categories of root cause (technical, organizational, human, patient related and other/unclassifiable) are divided into 20 subcategories. Full descriptions of the categories are given in Table 1. Mean values, median values, interquartile ranges and ranges (excluding outliers) are represented by circles, bold horizontal bars, boxes and error bars respectively. Outliers (more than 1.5 times the interquartile range) are represented by asterisks. A large box means that there is wide variation between units in the frequency of these root causes 
Wagtendonk, I. van, Smits, M., Merten, H., Heetveld, M.J., Wagner, C. Nature, causes and consequences of unintended events in surgical units. British Journal of Surgery: 2010, 97(11) $1730-1740$

\section{Table 5}

Table 5 Preventability of adverse events identified by review of 320 patient records

\begin{tabular}{|c|c|c|}
\hline $\begin{array}{l}\text { Degree of } \\
\text { preventability }\end{array}$ & $\begin{array}{l}\% \text { of adverse } \\
\text { events }\end{array}$ & Examples \\
\hline Virtually no evidence of preventability & 40 & $\begin{array}{l}\text { Development of pneumonia despite prophylactic antibiotics } \\
\text { Deep venous thrombosis despite prophylaxis } \\
\text { Wound infection after repeat surgery }\end{array}$ \\
\hline $\begin{array}{l}\text { Slight to modest evidence of } \\
\text { preventability }\end{array}$ & 7 & Delayed surgery for suspected diverticulitis \\
\hline $\begin{array}{l}\text { Preventability not very likely, less than } \\
50-50 \text {, but 'close call' }\end{array}$ & 15 & Leakage of bowel anastomosis and wound infection; no antibiotic prophylaxis \\
\hline $\begin{array}{l}\text { Preventability more than likely, more } \\
\text { than } 50-50 \text {, but 'close call' }\end{array}$ & 14 & $\begin{array}{l}\text { Postoperative pneumonia after laparotomy with insufficient pain treatment and no } \\
\text { respiratory exercise } \\
\text { Reoperation for leakage of bowel anastomosis in a diabetic patient on warfarin } \\
\text { complicated by haemorrhage due to uncorrected coagulopathy and second bowel } \\
\text { perforation necessitating multiple relaparotomies }\end{array}$ \\
\hline Strong evidence of preventability & 12 & $\begin{array}{l}\text { Insufficient CT-guided percutaneous drainage of an appendicular abscess; multiple } \\
\text { reinterventions necessary } \\
\text { Haemorrhage and gastric perforation after gastric banding without postoperative ICU } \\
\text { monitoring }\end{array}$ \\
\hline $\begin{array}{l}\text { (Virtually) certain evidence of } \\
\text { preventability }\end{array}$ & 12 & $\begin{array}{l}\text { Unrecognized septic shock and wound infection due to leakage of bowel anastomosis, } \\
\text { which in retrospect was clinically evident; delayed relaparotomy } \\
\text { Clinically palpable malignancy evident at physical examination, but missed initially }\end{array}$ \\
\hline Total & 100 & \\
\hline
\end{tabular}

CT, computed tomography; ICU, intensive care unit. 